\title{
Potential Vorticity Dynamics of the Arctic Halocline
}

\author{
Michael SPALL \\ Woods Hole Oceanographic Institution, Woods Hole, Massachusetts
}

(Manuscript received 10 March 2020, in final form 29 June 2020)

\begin{abstract}
An idealized two-layer shallow water model is applied to the study of the dynamics of the Arctic Ocean halocline. The model is forced by a surface stress distribution reflective of the observed wind stress pattern and ice motion and by an inflow representing the flow of Pacific Water through Bering Strait. The model reproduces the main elements of the halocline circulation: an anticyclonic Beaufort Gyre in the western basin (representing the Canada Basin), a cyclonic circulation in the eastern basin (representing the Eurasian Basin), and a Transpolar Drift between the two gyres directed from the upwind side of the basin to the downwind side of the basin. Analysis of the potential vorticity budget shows a basin-averaged balance primarily between potential vorticity input at the surface and dissipation at the lateral boundaries. However, advection is a leading-order term not only within the anticyclonic and cyclonic gyres but also between the gyres. This means that the eastern and western basins are dynamically connected through the advection of potential vorticity. Both eddy and mean fluxes play a role in connecting the regions of potential vorticity input at the surface with the opposite gyre and with the viscous boundary layers. These conclusions are based on a series of model runs in which forcing, topography, straits, and the Coriolis parameter were varied.
\end{abstract}

\section{Introduction}

The Arctic Ocean is mostly surrounded by land and is connected to lower-latitude oceans by only a few shallow and/or narrow straits. The largest exchange is found in the Fram Strait, which connects the Arctic Ocean to the Nordic seas and, ultimately, the Atlantic Ocean. Some waters flowing northward from the Atlantic Ocean through the Nordic seas are diverted away from Fram Strait into the Barents Sea just to the east. These two passages provide for the primary gateway for the approximately $9 \mathrm{~Sv}\left(1 \mathrm{~Sv}=10^{6} \mathrm{~m}^{3} \mathrm{~s}^{-1}\right)$ of warm and salty Atlantic Water to enter the Arctic Ocean (Østerhus et al. 2019). Most of the Atlantic Water recirculates through the Arctic, some close to Fram Strait and some traveling all the way around the Arctic Basin, to exit southward through Fram Strait (Rudels 2012). While in the Arctic, some of this Atlantic Water has become denser, forming a lower overturning branch, and some has become more buoyant by mixing with the overlying waters of lower salinity, forming an upper overturning branch (Rudels 2012). There is also a source of approximately $1 \mathrm{~Sv}$ of colder and fresher Pacific Water that flows through the Bering Strait (Woodgate et al. 2012). Most of this water

Corresponding author: Michael Spall,mspall@whoi.edu mass leaves the Arctic shelf near the Chukchi Sea via Barrow Canyon and the adjacent shelfbreak (Spall et al. 2018; Timmermans et al. 2014; Spall et al. 2008). Once in the interior, the Pacific Water is advected in the anticyclonic Beaufort Gyre and into the Transpolar Drift (Aksenov et al. 2016). These Pacific Waters exit the Arctic Ocean through both the narrow passages of the Canadian Arctic Archipelago and Fram Strait (Jones et al. 1998; Aksenov et al. 2016). Significant low-salinity waters are also provided to the Arctic interior from river outflows along the Siberian and Alaskan coasts (Haine et al. 2015; Rudels 2012).

The upper Arctic Ocean is dominated by two water masses: the halocline and the Atlantic Water. The halocline is a cold, freshwater mass of between 50- and 250-m thickness, thicker in the Canada Basin of the western Arctic and thinner in the Eurasian Basin of the eastern Arctic (Aagaard et al. 1981). The Atlantic Water is a relatively warm, salty water mass of Atlantic origin that is $300-500 \mathrm{~m}$ thick and lies below the halocline. The presence of the halocline blocks the heat contained in the Atlantic Water from direct contact with, and melting of, the overlying sea ice. The composition of the halocline varies across the Arctic. In the eastern Arctic, there is a single cold halocline composed primarily from Siberian river runoff (Aagaard et al. 1981; Rudels et al. 1996). 

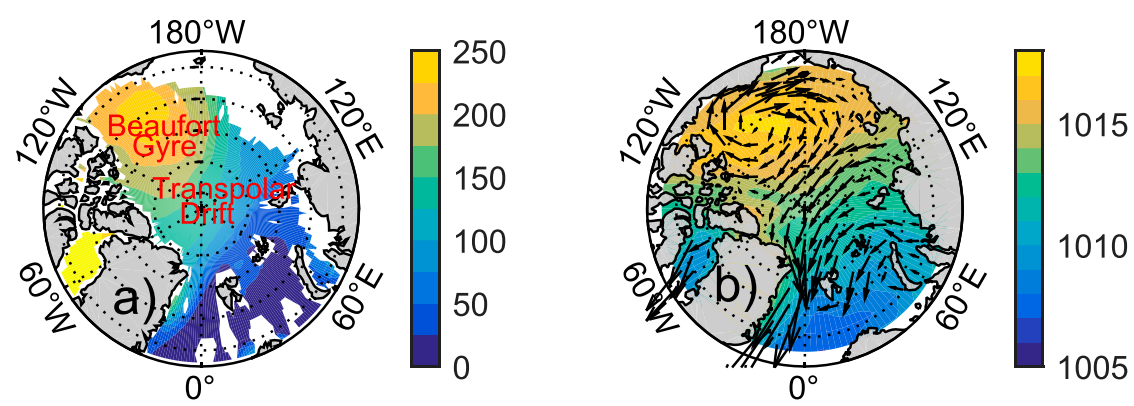

FIG. 1. (a) Mean depth of the 27.4 potential density surface [calculated from the Polar Science Center Hydrographic Climatology, version 3.0 (PHC3.0)]. (b) Mean sea level pressure (colors) and ice motion (vectors). The ice drift comes from the National Snow and Ice Data Center ICESat data averaged between 2004 and 2009, and the sea level pressure is from the NCEP reanalysis.

In the western Arctic, the upper halocline is formed from both river runoff and low-salinity waters from the North Pacific Ocean via transport through Bering Strait (Shimada et al. 2005), while the lower halocline is formed from a combination of Pacific-origin water, hypersaline waters formed in polynyas, and by mixing of Pacific-origin water with Atlantic water over the shelf (Woodgate et al. 2005).

The circulation within the halocline is dominated by two features: the Beaufort Gyre (BG) in the western Arctic and the Transpolar Drift (TPD) in the central and eastern Arctic (Fig. 1). Both are thought to be primarily wind-driven, either directly in regions of open ocean or indirectly through stress transmitted by the overlying ice. The Beaufort Gyre is approximately $250 \mathrm{~m}$ thick in the center and shallows toward the edges, forming a bowl of buoyant water that drives an anticyclonic circulation within the halocline. The potential vorticity of the halocline is controlled by its thickness, and so is low in the western Arctic and high in the eastern Arctic with the transition occurring across the Transpolar Drift. The Transpolar Drift advects water from the shelves near Russia across the pole toward Greenland and Canada before turning to flow out Fram Strait. These circulation patterns are reflected in the mean ice drift (Fig. 1b). The surface winds in the central Arctic are largely directed from Russia toward Greenland, as represented by the atmospheric surface pressure in Fig. 1b, while in the western Arctic they are anticyclonic around the Beaufort high. The sense of the curl forcing the ocean is anticyclonic in the western Arctic, weak in the central Arctic, and cyclonic in the eastern Arctic and northern Nordic seas.

Theoretical understanding of the circulation within the halocline has been developed primarily for the winddriven Beaufort Gyre in the Canada Basin. This understanding builds on an adiabatic and inviscid framework in which wind-forcing along closed circulation contours is balanced by lateral eddy fluxes across those contours. Geometrically, the Beaufort Gyre has some common elements with the Antarctic Circumpolar Current in the Southern Ocean and the midlatitude atmospheric jet stream, where these ideas were first developed (Andrews and McIntyre 1976; Marshall and Radko 2003). Davis et al. (2014), Manucharyan and Spall (2016), and Manucharyan et al. (2016) applied a transformed Eulerian mean approach to derive analytic estimates of the mean and time-dependent response of the Beaufort Gyre to an applied surface wind stress. Meneghello et al. (2018) added a conceptual ice model to this wind-forced system by allowing the stress to depend on the difference between the ocean velocity and the ice velocity. This reduced the effective annual mean stress applied to the ocean (but not the sign) and the level of eddy activity required to balance the atmospheric forcing. These models treat the Beaufort Gyre as isolated from the rest of the Arctic Ocean and consider only anticyclonic surface stress curl. The vorticity input by the wind is balanced by friction at the side-wall boundary with eddies serving to communicate the low potential vorticity from its source in the interior to the sink at the boundary (Yang et al. 2016). The real Beaufort Gyre, however, has a coast only over a small fraction of the gyre and the offshore side of the gyre is not geographically constrained.

The surface stress applied to the ocean in the central and eastern Arctic includes regions of cyclonic curl. This can be seen in the ice motion in Fig. 1 and is also reflected in the surface atmospheric pressure. A cyclonic curl in ice motion within the TPD is also predicted by the theoretical model of Spall (2019), even if there is no curl in the surface winds, due to the internal ice dynamics. The geometry of the Arctic basin and the presence of cyclonic curl in the eastern Arctic prompt the question 

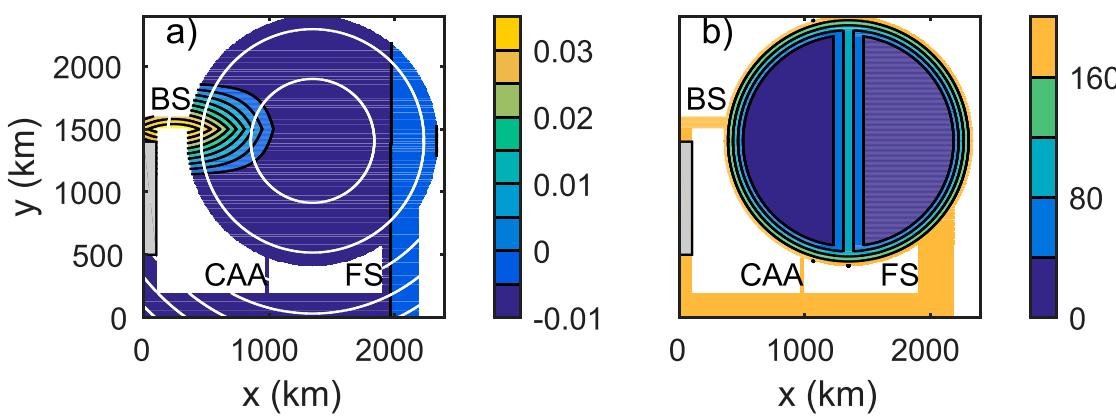

FIG. 2. (a) Model domain with meridional surface stress (colors; $\mathrm{N} \mathrm{m}^{-2}$ ) and Coriolis parameter (white contours, with contour interval of $1 \times 10^{-6} \mathrm{~s}^{-1}$ ). (b) Bottom topography (m), including a continental slope and midocean ridge used for calculations in section 4 . Straits are marked as BS: Bering Strait, CAA: Canadian Arctic Archipelago, and FS: Fram Strait. The transport through Bering Strait is set within the gray-shaded region along the western boundary.

of how dynamically isolated the region of anticyclonic wind stress curl in the western Arctic is from the rest of the Arctic basin. Also, the influence of Pacific-origin waters flowing through Bering Strait on the circulation across the Arctic basin is unknown. The objective of the present study is to understand how both anticyclonic and cyclonic surface stresses and the inflow of Pacific Water act together to determine the halocline depth and drive the dominant circulation patterns in the Arctic Ocean.

\section{An idealized model for the Arctic halocline}

A two-layer shallow water numerical model is now developed for the Arctic halocline. It is emphasized that this configuration is not intended to represent the real Arctic Ocean in either physical or geometrical complexity. It is designed to retain the forcing mechanisms for the dominant circulation features in the halocline (the Beaufort Gyre and the Transpolar Drift) and the influence of Pacific Water while still easily manipulated in forcing and diagnostics to reveal the physics that control the circulation. The model Arctic basin is a circle of $2000 \mathrm{~km}$ diameter that has three straits representing Fram Strait, Bering Strait, and the Canadian Arctic Archipelago (Fig. 2). The initial layer thicknesses are $H_{1}=200 \mathrm{~m}$ and $H_{2}=400 \mathrm{~m}$ with a reduced gravity between the two layers of $g^{\prime}=0.025 \mathrm{~m}^{2} \mathrm{~s}^{-1}$. This is of course much shallower than the real Arctic Ocean and is intended to represent only the halocline and Atlantic Water layers. This stratification gives a baroclinic deformation radius of $13 \mathrm{~km}$, which is about 2 times the model grid spacing of $6.67 \mathrm{~km}$. The pole is located at the center of the basin with the Coriolis parameter defined as for a spherical grid, $f=2 \Omega \sin (\pi / 2-\phi r)$, where $\Omega=7.27 \times 10^{-5} \mathrm{~s}^{-1}$ is the rotation rate of Earth, $\phi=1.57 \times 10^{-7} \mathrm{~m}^{-1}$ is radians per meter of latitude, and $r$ is the distance from the pole.

Bottom topography can have a controlling influence on the large-scale flow, especially in regions of shallow and/or steep topography. Topography alters the layer-2 geostrophic contours (contours of $f / h_{2}$ ), which is expected to strongly influence the mean flow, at least in layer 2. To the extent that the two layers are coupled through baroclinic instability, it is also expected that the topography will influence the mean circulation in the upper layer. In addition, bottom slopes can stabilize baroclinic flows (Blumsack and Gierasch 1972; Isachsen 2011; Manucharyan and Isachsen 2019), which is potentially important for boundary currents in the Arctic. To test these influences, topography including a continental slope and ridge was considered (Fig. 2b). The slope is $200 \mathrm{~km}$ wide with a maximum topographic height of $200 \mathrm{~m}$. The ridge also decays over a horizontal scale of $200 \mathrm{~km}$ but has a maximum topographic height of $100 \mathrm{~m}$. The shorter ridge topography allows for some topographic contours to pass unobstructed between the western and eastern basins. Separate calculations are carried out with just the slope, just the ridge, and both the slope and ridge. Although these features are not as tall as in the real ocean, the model does not represent the deepest layers and this height represents approximately $25 \%-50 \%$ of the layer- 2 thickness and so provides a significant gradient in the layer-2 potential vorticity, which is the dynamically important function of the bottom topography. The model numerics do not allow for either layer to vanish, so this topography provides the influence of the bottom slope without violating the model equations.

The circulation is forced by an applied surface stress and an inflow through the model Bering Strait. The stress pattern is idealized but represents the strong 
anticyclonic Beaufort high in the western Arctic and the weaker cyclonic curl found in the eastern Arctic (Fig. 2a). The stress is directed from the model "Russia" toward "Greenland" over most of the basin with a reversal near the Bering Strait inflow to represent the westward wind found along the southern flank of the Beaufort high. Although there is no ice in the model, the stress can be thought of as that imparted onto the ocean through either wind or ice movement (Fig. 1b). This forcing represents the annual mean. It is likely that seasonal variability would result in time periods for which the strength and even the sign of the surface stress will change, as found by Meneghello et al. (2018) in the Beaufort Gyre region. Nonetheless, the annual mean surface stress must take the general sign and pattern of that imposed here, and so the dynamics explored here remain relevant for the mean circulation in the Arctic even with sea ice.

The inflow through Bering Strait is forced by imposing a uniform flow of magnitude $U_{\text {in }}=0.05 \mathrm{~m} \mathrm{~s}^{-1}$ in the upper layer and zero in the lower layer within the narrow gray region in the channel on the left side of the domain (Fig. 2). The layer thicknesses are also restored with a time scale of 1 day toward $h_{1}^{*}=H_{1}-\left(x_{e}-x\right) f U_{\text {in }} / g^{\prime}$, and $h_{2}^{*}=H_{1}+H_{2}-h_{1}^{*}-H_{b}^{*}$, where $x_{e}=100 \mathrm{~km}$ is the righthand side of the channel and $H_{b}^{*}$ is the height of the bottom topography within the restoring region. This results in an inflow of strength of $1 \mathrm{~Sv}$, consistent with recent estimates of the transport through Bering Strait (Woodgate 2018). This also sets the layer thickness on the boundary on both sides of the model Bering Strait. Most of this transport in the model enters the basin and turns toward the west, analogous to the Chukchi Slope Current (Corlett and Pickart 2017; Spall et al. 2018). This inflow exits through the two remaining straits that represent Fram Strait (FS) and the Canadian Arctic Archipelago (CAA). The relative transport through each strait depends on a circulation integral around the boundary of the island that represents Greenland (Joyce and Proshutinsky 2007). Because this is a closed contour along a solid boundary, an integral of the momentum equation tangent to the island boundary requires that surface stress be balanced by dissipation. If the dissipation on one side of the island is reduced, this requires that the flow adjust such that dissipation on the other side of the island is also reduced. The width of the CAA in the model is $40 \mathrm{~km}$ and was chosen such that about half of the inflow through Bering Strait flows out the CAA and half flows out FS. If the CAA is made wider, the friction on the west side of "Greenland" is reduced, which then requires weaker dissipation and reduced transport on the eastern side of the island.
The shallow water momentum equations may be written as

$$
\begin{aligned}
\frac{\partial u_{k}}{\partial t}+\left(f+\zeta_{k}\right) v_{k}= & -\frac{\partial\left(P_{k}+E_{k}\right)}{\partial x}-(k-1) C_{d} u_{k} \\
& +A \nabla^{2} u_{k} \quad \text { and } \\
\frac{\partial v_{k}}{\partial t}-\left(f+\zeta_{k}\right) u_{k}= & (2-k) \frac{\tau^{y}}{\rho_{0} h_{k}}-\frac{\partial\left(P_{k}+E_{k}\right)}{\partial y} \\
& -(k-1) C_{d} v_{k}+A \nabla^{2} v_{k},
\end{aligned}
$$

where $k=1,2$ is the layer, $u$ and $v$ are the horizontal velocities in the $x$ and $y$ directions, $h$ is the layer thickness, $\tau^{y}$ is the stress in the $y$ direction, $\zeta_{k}=\partial v_{k} / \partial x-\partial u_{k} / \partial y$ is the relative vorticity, $E_{k}=\left(u_{k}^{2}+v_{k}^{2}\right) / 2$ is the kinetic energy, $g^{\prime}=\left(\rho_{2}-\rho_{1}\right) g / \rho_{2}$ is the reduced gravity, and $\rho_{0}$ is a reference density. The pressure is calculated from the hydrostatic equation as

$$
P_{1}=g\left(h_{1}+h_{2}+H_{b}\right) \text { and } P_{2}=P_{1}-g^{\prime} h_{1},
$$

where $H_{b}$ is the bottom topography.

The continuity equation is

$$
\frac{\partial h_{k}}{\partial t}+\nabla \cdot\left(h_{k} \mathbf{u}_{k}\right)=w *(3-2 k) H_{1} / h_{1}
$$

where $w^{*}$ is a spatially uniform diapycnal mass flux, positive directed from layer 2 into layer 1 . This is a parameterization of diapycnal mixing at the layer interface. Most of the model runs are adiabatic with $w^{*}=0$, so there is no mixing or mass flux between layers (outside the restoring region in the western channel). The parameterization in (3) results in larger diapycnal mass flux (representing larger diapycnal mixing) in regions where the upper layer is thin. This is motivated by the expectation that mixing is a result of energy generated at the surface by wind stress or ice motion and that the resulting mixing will be larger when the interface with the Atlantic Water layer is closer to the surface. The overall influence of diapycnal mixing is not strongly dependent on the specific formulation, similar results are found for spatially uniform diapycnal mixing.

Subgrid-scale mixing is represented by the deformationdependent viscosity of Smagorinsky (1963) in each layer with no-slip lateral boundary conditions. The horizontal viscosity coefficient $A$ is defined as

$$
A=\left(\nu_{s} / \pi\right)^{2} \Delta^{2}\left[\left(\frac{\partial u}{\partial x}-\frac{\partial v}{\partial y}\right)^{2}+\left(\frac{\partial u}{\partial y}+\frac{\partial v}{\partial x}\right)^{2}\right]^{1 / 2},
$$

where $\nu_{s}=3.5$ is a nondimensional coefficient and $\Delta$ is the model grid spacing. There is also a linear bottom 
drag added to layer 2 in (1) with coefficient $C_{d}=3 \times$ $10^{-6} \mathrm{~s}^{-1}$. A Reynolds number may be calculated for the flow, defined as $\operatorname{Re}=V L / A$, where $L$ is the basin radius and $V$ is a typical horizontal velocity. Making use of (4), the viscosity scales as $A \propto(\nu / \pi)^{2} \Delta V$, where it has been assumed that the velocity varies by $O(V)$ over the grid scale $\Delta$. This gives a Reynolds number that is independent of the forcing strength, $\operatorname{Re}=(\pi / \nu)^{2}(L / \Delta)=120$ for the present configuration.

A passive tracer $T$ is used to mark the time since a parcel has been introduced to the Arctic basin through Bering Strait. The governing equation is

$$
\frac{\partial T}{\partial t}+\nabla \cdot\left(\mathbf{u}_{k} T\right)=1+A_{T} \nabla^{2} T
$$

The tracer is set to zero in the forcing region within the western channel and grows linearly in time elsewhere. The tracer is also set to the integration time within the model Fram Strait to distinguish between waters that recirculate with the Arctic basin and those that recirculate through Fram Strait. There is a weak Laplacian diffusion of strength $A_{T}=10 \mathrm{~m}^{2} \mathrm{~s}^{-1}$ applied to suppress noise at the grid level.

An equation for the evolution of potential vorticity, defined as $q=(f+\zeta) / h$, can be derived from (1) and (3) by recognizing that

$$
\zeta_{t}=(h q)_{t}=h q_{t}+q h_{t} .
$$

The left-hand side can be derived by taking the curl of the momentum equations in (1), while the second term on the right-hand side is derived from the continuity equation in (3). This construct differs substantially from the relative vorticity equation considered by Yang et al. (2016) because it includes the influence of layer thickness on the potential vorticity. The resulting equation for the evolution of potential vorticity in layer 1 is

$$
\begin{aligned}
\underbrace{\frac{\partial q}{\partial t}=}_{\text {TEND }} & \underbrace{\frac{f+\zeta}{h^{2}} \mathbf{u} \cdot \nabla h}_{\text {THICK }}-\underbrace{\frac{\mathbf{u}}{h} \nabla \cdot(f+\zeta)}_{\text {VORT }}+\underbrace{\frac{1}{h} \frac{\partial}{\partial x}\left(\frac{\tau^{y}}{\rho_{0} h}\right)}_{\text {STRESS }} \\
& +\underbrace{\frac{1}{h} \nabla \times\left(A \nabla^{2} \mathbf{u}\right)}_{\text {FRICTION }}-\underbrace{\frac{f+\zeta}{h^{3}} w^{*} H_{1}}_{\text {MIX }},
\end{aligned}
$$

where the subscript for the layer number has been omitted for clarity, the horizontal velocity is now written in vector form. The labels below the equation will be used in the following discussion. The first term on the right-hand side is the potential vorticity tendency due to the advective thickness flux divergence, and the second term on the right-hand side is due to the flux divergence of absolute vorticity. These could be combined into the flux divergence of potential vorticity but keeping them separate is more consistent with the shallow water equations solved by the model. THICK and MIX are derived from the continuity equation; VORT, STRESS, and FRICTION are derived from the momentum equations.

There is no exchange of potential vorticity between layers resulting from interface displacements associated with eddy fluxes. Although eddies arising due to baroclinic instability can flux momentum downward from layer 1 to layer 2, the potential vorticity flux is identically zero. This is because the interface is displaced at exactly the same rate as the velocity that advects potential vorticity perpendicular to the interface, and so there is no net flux through the interface. This is known as the impermeability theorem, introduced by Haynes and McIntyre (1987). That same theorem finds that diapycnal mixing also does not alter the volume integral of potential vorticity, while the diapycnal mixing term does enter (7). The reason is that the impermeability applies to the volume integral whereas (7) is only the twodimensional layer average. If one integrates (7) over the layer thickness, the MIX term is exactly canceled by the change in volume. For example, for $w^{*}>0, q_{t}<0$ and the local potential vorticity decreases. However, the layer thickness increases by an amount that exactly offsets this decrease so that the layer integral of potential vorticity is unchanged.

\section{An illustrative example}

The forcing described in the previous section was applied to the model for a period of 100 years. The mean transport streamfunction for each layer (averaged over the final 50 years of integration) and layer thickness and potential vorticity for the upper layer are shown in Fig. 3. The flow is dominated by an anticyclonic circulation in the western basin and a weaker cyclonic circulation in the eastern basin. The anticyclonic circulation extends beyond the region of anticyclonic forcing and both gyres are rotated clockwise around the basin relative to the applied stress (the dashed line marks the transition from anticyclonic to cyclonic curl). The region between the two gyre centers transports water from the upwind coast to the downwind coast. Upon encountering the downwind coast the transport either: recirculates in the eastern basin, flows out the western strait (the Canadian Arctic Archipelago) or flows out the eastern strait (Fram Strait). This general circulation pattern is consistent with the anticyclonic Beaufort Gyre in the Canada Basin, the Transpolar Drift, which flows from Russia toward Greenland, and the cyclonic circulation found in the Eurasian Basin (Fig. 1). 

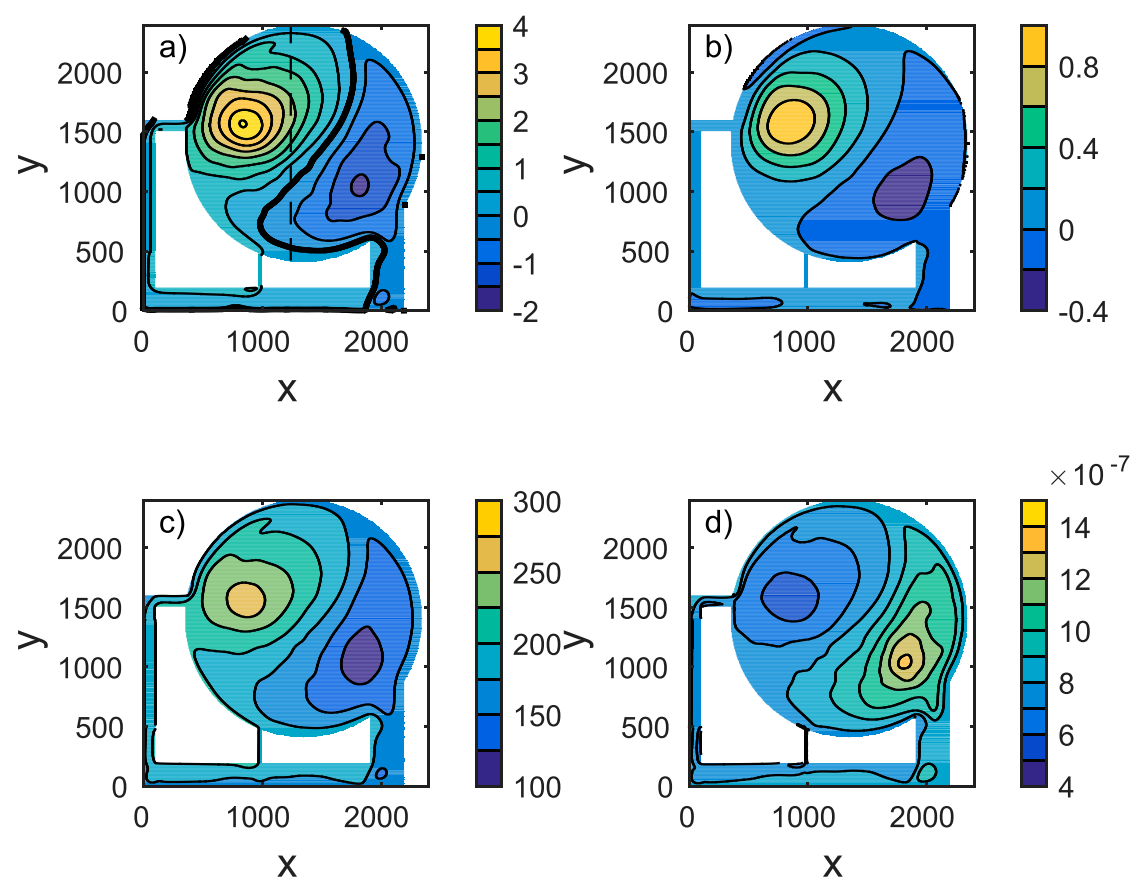

FIG. 3. Mean over the final 50 years of integration for (a) layer-1 transport streamfunction (Sv), (b) layer-2 transport streamfunction (Sv), (c) layer-1 thickness (m), and (d) layer-1 potential vorticity $\left(\mathrm{m}^{-1} \mathrm{~s}^{-1}\right)$. The dashed line in (a) marks the transition from anticyclonic to cyclonic curl.

The transport into the basin through the model Bering Strait is approximately $1 \mathrm{~Sv}$, which turns toward the west upon entering the basin. This is consistent with the formation of the Chukchi Slope Current from the outflow of Pacific-origin waters flowing through Barrow Canyon (Corlett and Pickart 2017; Spall et al. 2018). This water flows anticyclonically around the Beaufort Gyre before entering the Transpolar Drift. About half of the $1 \mathrm{~Sv}$ exits the Arctic basin through the CAA and half through FS, as intended through the choice of the width of the CAA. The thick line in Fig. 3a marks the 1-Sv contour, approximately separating the direct influences from the Bering Strait inflow and the recirculation in the eastern Arctic. The transport streamfunction in layer 2 has the same sense as that in layer 1 but is much weaker (Fig. 3b). This deep circulation is driven by baroclinic instability and the associated vertical flux of horizontal momentum since there is no external forcing or imposed interfacial stress applied to this layer. The strength is determined primarily by a balance between the downward flux of momentum and linear bottom drag such that smaller values of $C_{d}$ result in a stronger mean circulation in the deep layer.

The upper-layer thickness reaches approximately $250 \mathrm{~m}$ in the western basin and shallows to almost $100 \mathrm{~m}$ in the eastern basin (Fig. 3c). The transition between the two basins supports the Transpolar Drift. The potential vorticity (Fig. 3d) is controlled by the layer thickness, and so is low in the anticyclonic gyre and high in the cyclonic gyre with a rapid transition across the TPD. This general pattern of layer thickness and potential vorticity is consistent with the climatology shown in Fig. 1.

An instantaneous view of the upper-layer transport streamfunction and potential vorticity reveals that the flow is highly time dependent (Fig. 4). The Beaufort Gyre is very irregular in shape, dominated by large-scale meanders and eddies. These synoptic features advect low-potential-vorticity water out of the center of the gyre and act to balance the anticyclonic stress curl and downward Ekman pumping (Davis et al. 2014; Manucharyan and Spall 2016; Manucharyan et al. 2016; Yang et al. 2016; Meneghello et al. 2018). There is also considerable meandering and eddy formation along the Transpolar Drift and along the westward-flowing high potential vorticity waters adjacent to the boundary downstream of Fram Strait. Eddies exchange water masses across the TPD, demonstrating that the eastern and western Arctic are dynamically connected.

The age tracer that marks the time since a water parcel exited Bering Strait is shown in Fig. 4d. Pacific-origin water flows anticyclonically around the western basin and mixes into the interior of the Beaufort Gyre by lateral eddy fluxes. The center of the Beaufort Gyre is a 

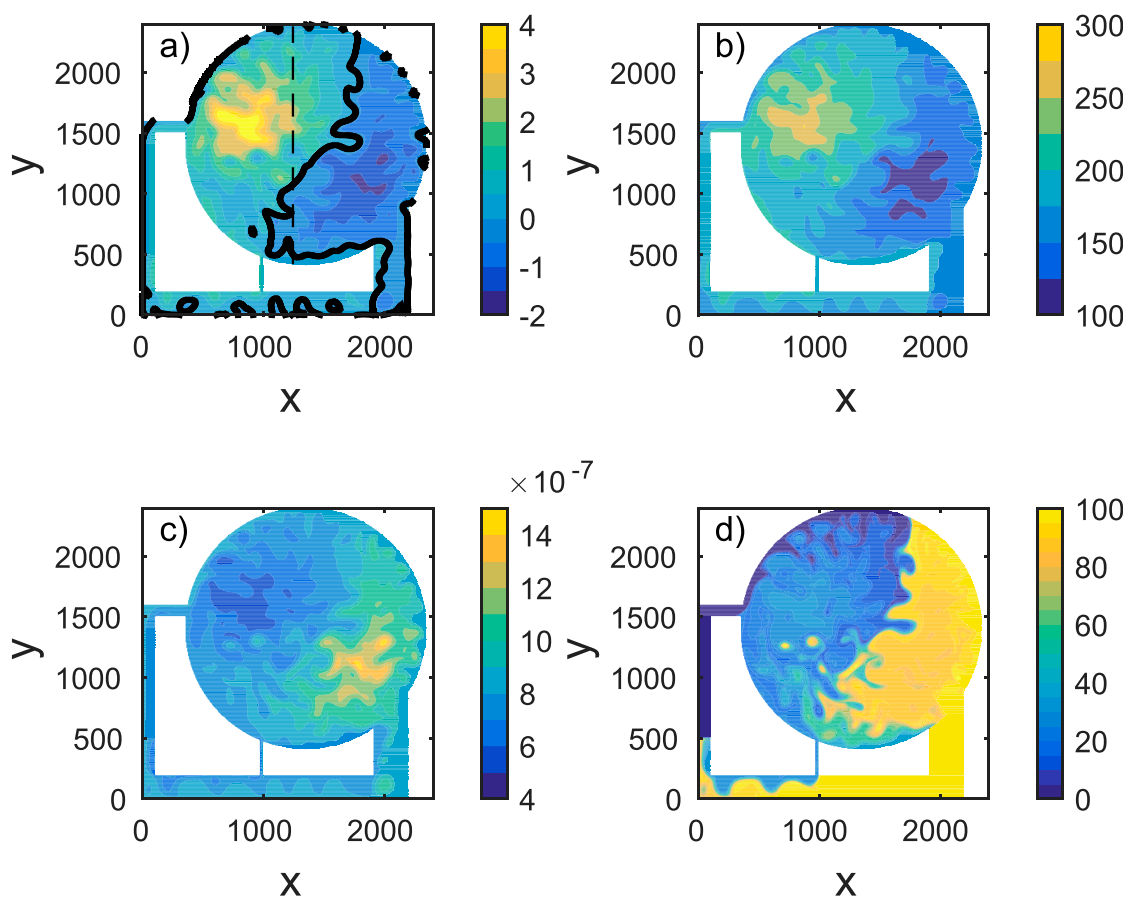

FIG. 4. Snapshot after 97 years of integration for layer-1 (a) transport streamfunction $(\mathrm{Sv}),(\mathrm{b})$ thickness $(\mathrm{m}),(\mathrm{c})$ potential vorticity $\left(\mathrm{m}^{-1} \mathrm{~s}^{-1}\right)$, and (d) age tracer since Bering Strait (years).

mean local maximum of about 25 years since water entered the basin. Water entering the basin interior via the Transpolar Drift along the upwind side of the basin has lower age, indicating a relatively rapid pathway to the basin interior. This pathway is analogous to the transport in the Chukchi Slope Current, although that current has not yet been traced with observations to the west of the Chukchi Plateau. There is a sharp transition between the western side of the TPD and the eastern side, where the mean water age is close to the 100-year integration time, indicating that the eastern basin has not yet equilibrated. This front broadens along the direction of the Transpolar Drift flow due to lateral eddy fluxes. It is expected that this transition would be wider if temporally variable surface stress was applied instead of the steady forcing used here. This general distribution and implied pathways are consistent with that found in more comprehensive general circulation models of the Arctic Ocean (Aksenov et al. 2016), lending confidence to the relevance of this idealized model for the general circulation in the Arctic halocline.

This representation of the Beaufort Gyre is broadly consistent with recent idealized models that are forced with localized anticyclonic stress curl. There are two important differences, however, in how the present model is forced. First, there is a source of relatively high potential vorticity waters to the western basin through the Bering Strait inflow. This alters the potential vorticity gradient along the southwestern portion of the gyre and also introduces an azimuthal asymmetry to the circulation. The second major difference is that there is a boundary only along the southern edge of the gyre, the poleward side of the gyre is locally unbounded. In the single-gyre, closed domain configuration used for the previous idealized models, there is a balance between vorticity input at the surface and vorticity dissipation along the boundary with eddies connecting the source and sink regions. In the following section potential vorticity budgets are used to demonstrate how consideration of the Pacific Water source and an eastern Arctic alter the dynamics of the Beaufort Gyre.

\section{Potential vorticity analysis}

The terms in the potential vorticity equation for layer 1 have been diagnosed from the model run. A time series of the basin-averaged contributions with a 12-month running average is shown in Fig. 5a. The net potential vorticity input by the surface stress is initially negative, reflecting the dominance of the anticyclonic curl in the western basin, yet quickly becomes positive, where it remains for the duration of the calculation. This is because the vorticity input depends not only on the surface stress, which is constant in time, but it is also inversely proportional to the square of the upper-layer thickness. 

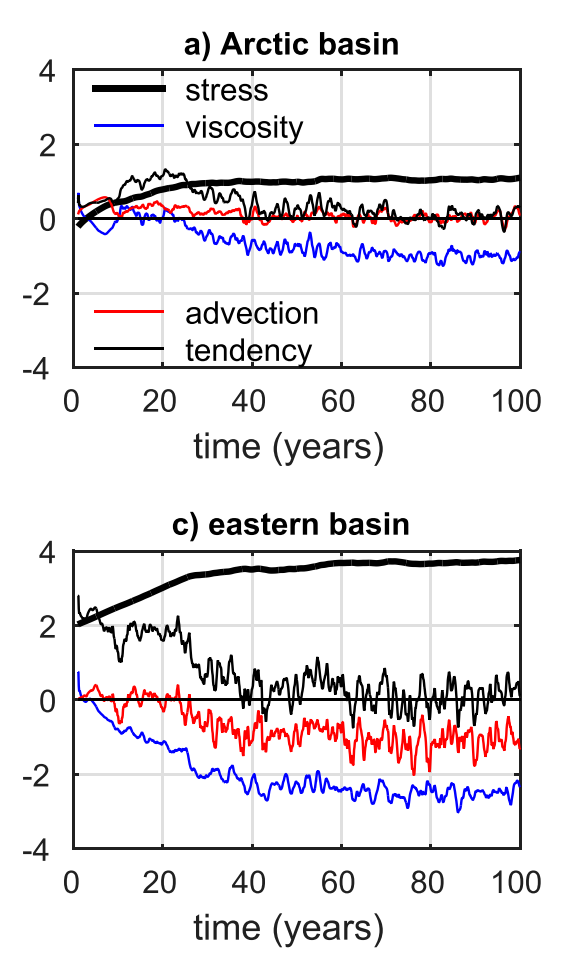

As the circulation spins up the potential vorticity input under cyclonic stress increases as the layer thickness in the eastern basin decreases. Conversely, the potential vorticity input under the anticyclonic stress decreases as the gyre deepens. This net positive potential vorticity input is balanced primarily by viscous dissipation at the boundaries, although there is a slightly positive net potential vorticity input due to advection as a result of the inflow through Bering Strait.

The eastern and western basins can be defined by the transition from zero or negative curl to positive curl, which takes place at $x=1240 \mathrm{~km}$ for this case (Fig. 3a). The vorticity terms when integrated over only the western basin show a different balance than for the basin as a whole (Fig. 5b). The curl of the surface stress is negative, as expected, although it does weaken slightly from its initial value as a result of the gyre deepening. The surface forcing is now balanced by both friction and advection [THICK and VORT in (7)], with advection almost 2 times as large as friction by the end of the integration. The spinup time scale is similar to that for the whole basin. Diagnosing the advection term reveals that it is dominated by the mean advection of layer thickness. The eddy flux terms are important in certain regions of the basin, however, as shown below. The advective tendency is of the opposite sign in the eastern basin (Fig. 5c), acting to reduce the potential vorticity. However, in the eastern basin, friction is more important than advection. This is because the basin is larger and

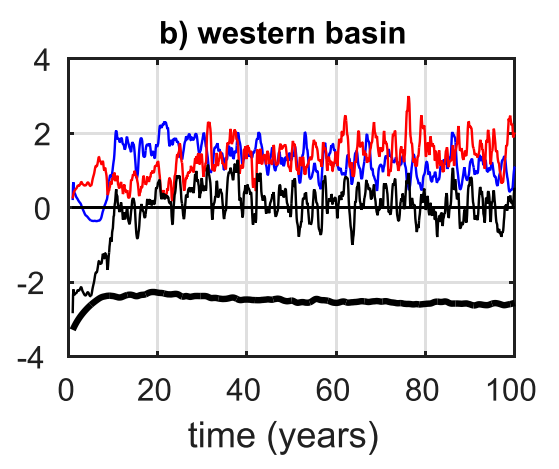

FIG. 5. Time series of terms in the potential vorticity equation $\left(10^{-16} \mathrm{~m}^{-1} \mathrm{~s}^{-2}\right)$ for layer 1 averaged over (a) the Arctic basin, (b) $x<1240 \mathrm{~km}$ (western basin), and (c) $x>1240 \mathrm{~km}$ (eastern basin). Thick black line: surface stress; blue line: viscosity; red line: advection; thin black line: tendency. there is more positive potential vorticity input by the surface stress so that the potential vorticity exchange with the western basin can account for less of the overall budget than it does in the western basin. The importance of the advection term in balancing the surface forcing highlights the nonlocal nature of the halocline dynamics within the Arctic basin and the communication between the eastern and western Arctic. This is analogous to the midlatitude potential vorticity flux between the subtropical and subpolar gyres exchanged across the Gulf Stream and North Atlantic Current (Marshall 1984; Lozier and Riser 1990; Fox-Kemper 2005).

Although the integrated vorticity budget shows a balance between forcing and dissipation, maps of the individual terms show a much more complex system (Fig. 6). The surface forcing follows the pattern of the stress curl, but the potential vorticity input in the eastern basin is enhanced and rotated relative to the western basin because of its dependence on layer thickness. Viscous dissipation along the boundary of the Beaufort Gyre is positive (producing cyclonic relative vorticity) and negative elsewhere along the boundary, where the flow is cyclonic (Fig. 6c). The boundary currents extend beyond the regions of anticyclonic and cyclonic forcing, highlighting the importance of nonlinear advection in the basin-scale circulation and potential vorticity budget. There are also regions of positive and negative dissipation in the interior where eddies decay, but the net dissipation away from the viscous boundary layers is 


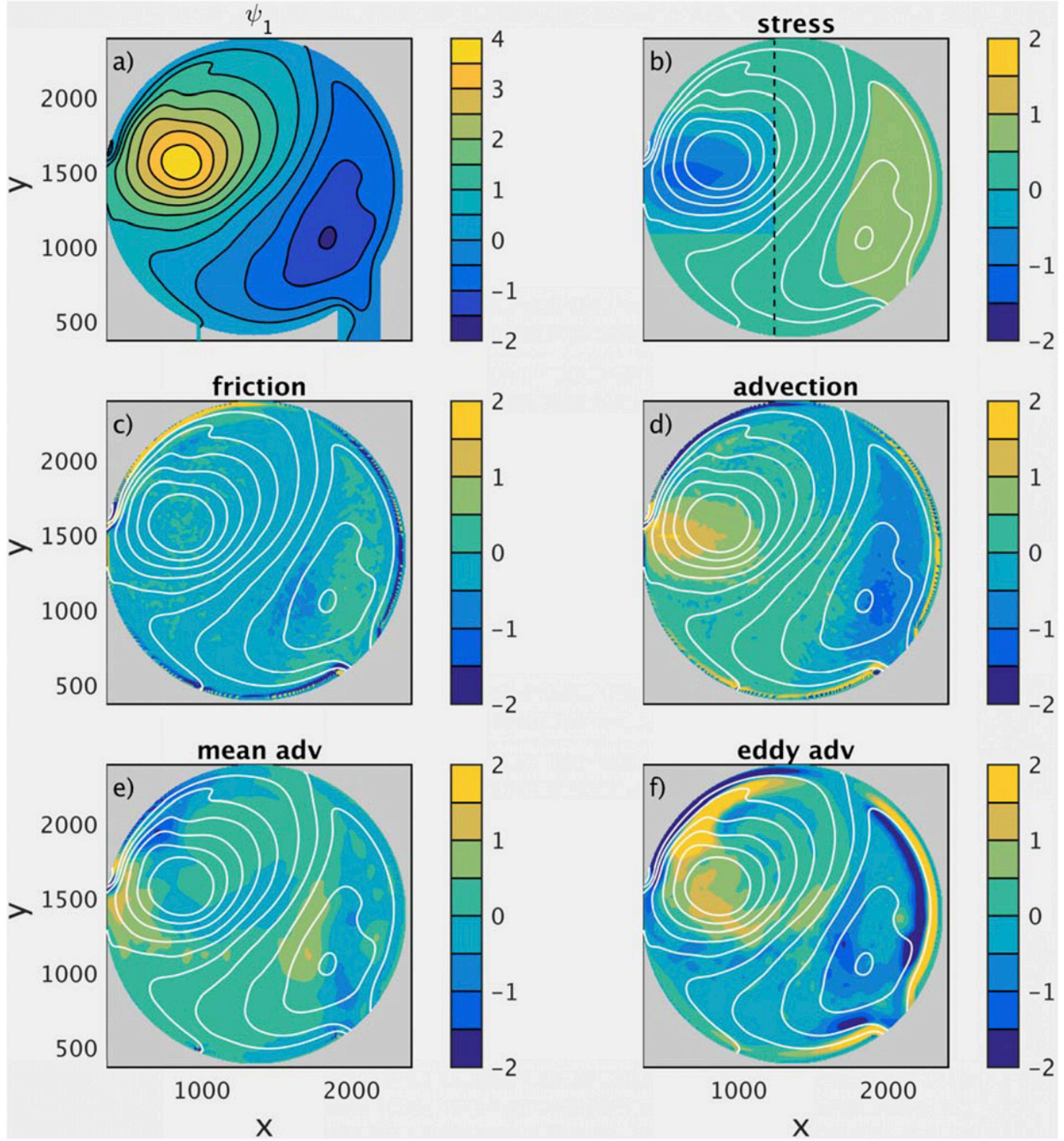

FIG. 6. Layer-1 (a) mean transport streamfunction (Sv). Also shown are the mean terms in the potential vorticity equation $\left(10^{-15} \mathrm{~m}^{-1} \mathrm{~s}^{-2}\right)$ for (b) surface stress, (c) viscosity, (d) advection, (e) mean advection, and (f) eddy advection. The black dashed line in (b) marks the transition from the western basin to the eastern basin, where the stress curl changes sign.

zero. The potential vorticity input by the surface stress is primarily balanced by lateral advection (Fig. 6d), positive in the western basin and negative in the eastern basin. Advection also balances dissipation in the narrow boundary layers.

The total advective flux divergence of potential vorticity has been decomposed into mean and eddy contributions (Figs. 6e,f). The region of anticyclonic stress curl is balanced by both mean and eddy fluxes. The eddy fluxes are dominant in the region of closed mean transport streamfunction that lies offshore of the boundary current. Eddies formed by baroclinic instability flux low potential vorticity out of the center of the gyre toward the edge (and high potential vorticity into the center of the gyre). This flattens the isopycnals and gives a positive tendency in the center of the gyre and a negative tendency along the edge of the gyre. The mean flux divergence is positive along the eastern flank of the gyre, balancing the stress curl and the eddy flux divergence. The mean circulation advects the low potential vorticity provided by eddies toward the boundary region along the eastern flank of the gyre. Near the boundary, just downstream of the Bering Strait inflow, eddies are fluxing high potential vorticity water from near the boundary into the 

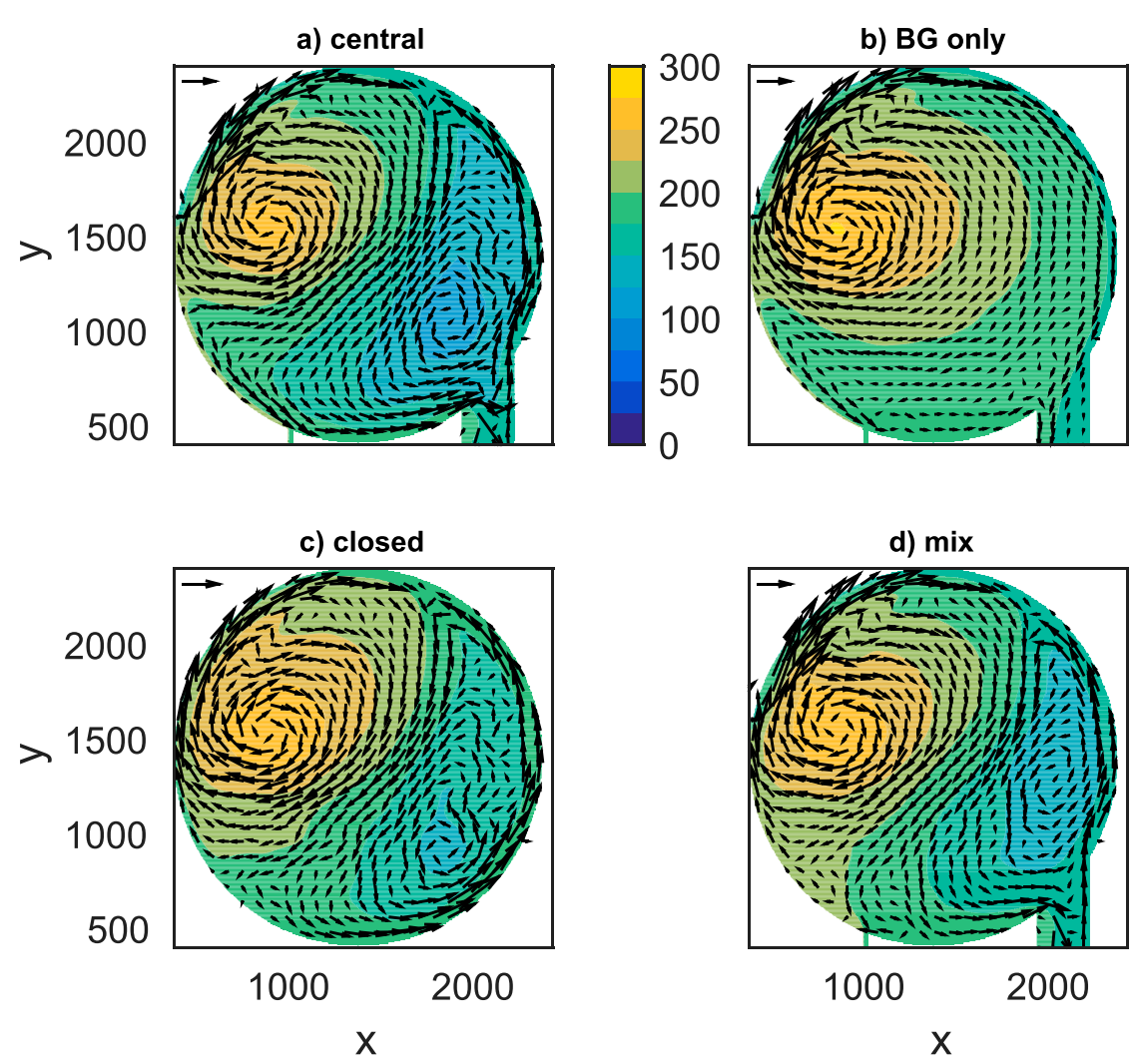

FIG. 7. Layer-1 thickness (m) and velocity (every twelfth grid point) for (a) the central case, (b) BG only, (c) the closed basin, and (d) diapycnal mixing. The vector in the upper-left corner of each panel indicates a speed of $5 \mathrm{~cm} \mathrm{~s}^{-1}$.

interior, giving rise to the region of strong positive tendency on the offshore side of the boundary current. The mean circulation advects this high potential vorticity water away, resulting in a strong negative tendency in the mean flux divergence that transitions to positive as that high potential vorticity fluid is advected around the gyre. The pattern in the central and eastern basin also reflects eddies transporting fluid down the mean potential vorticity gradient, decreasing potential vorticity in the center of the eastern gyre and transporting it both into the boundary layers and to the periphery of the gyre, where mean advection takes it away.

\section{Parameter sensitivities}

The model configuration in the previous section represents the main elements of the wind- and ice-forced halocline circulation. Several additional configurations are now considered in order to better understand the influences of the applied stress, Bering Strait inflow, and the domain configuration.

The influences on the circulation are first demonstrated through changes in the mean thickness and horizontal velocity of layer 1 . Figure 7 a shows the layer thickness and velocity in layer 1 for the central case. The flow is dominated by the Beaufort Gyre, TPD, and boundary currents. The layer thickness and velocity for a calculation with only the anticyclonic stress curl is shown in Fig. 7b. The upper layer is now much thicker in the eastern basin and the circulation is anticyclonic all across the basin, extending far from the region of anticyclonic forcing. However, the layer thickness and anticyclonic circulation in the western basin are also enhanced, indicating that the stress applied in the eastern basin also influences the circulation and halocline thickness in the western basin. The maximum mean transport streamfunction in the western basin has increased from $3.95 \mathrm{~Sv}$ for the central case to $4.74 \mathrm{~Sv}$ for this case (Fig. 8).

A calculation with the same stress as the central case but with no inflow/outflow to the basin is shown in Fig. 7c. The largest differences are found near the straits. The loss of the inflow of Pacific-origin water reduces the transport along the boundary between the inflow at BS and the outflow at the CAA. The circulation downstream of the BS inflow is also weakened (less anticyclonic) 


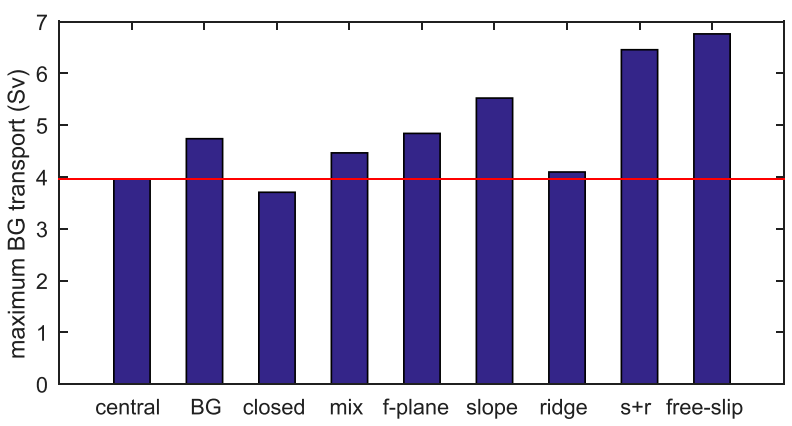

FIG. 8. Maximum mean layer-1 transport streamfunction (Sv) in the western basin for each of the model runs. The red line marks the BG transport for the central case for easy comparison with the gyre strength for the other calculations.

because some of the inflow initially penetrates into the basin interior. The transport of the model Beaufort Gyre is also slightly reduced (Fig. 8). The halocline is gradually thicker moving from the western basin to the eastern basin than it is the case with an open Bering Strait, indicating that even though little Pacific-origin water directly reaches the eastern basin the halocline there is influenced by the inflow of PW. The 1-Sv transport of Pacific Water through the basin requires a change in layer thickness from east to west of approximately $25 \mathrm{~m}$ (for a mean layer thickness of $200 \mathrm{~m}$ and a reduced gravity of $0.025 \mathrm{~m}^{2} \mathrm{~s}^{-1}$ ), so the loss of that transbasin transport requires a smaller change in layer thickness across the basin. The adjustment of the layer thickness across the Arctic to the imposed transport through BS is communicated through the pressure propagated by boundary waves, and so the eastern basin is influenced by the BS inflow even though the waters do not directly enter the eastern basin.

All calculations to this point have been adiabatic (outside the forcing region in the channel). However, in the real Arctic there is weak mixing between the halocline and the warmer Atlantic Waters below. The influence of diapycnal mixing is demonstrated by setting $w^{*}=3.185 \times 10^{-8} \mathrm{~m} \mathrm{~s}^{-1}$. This would provide $0.1 \mathrm{~Sv}$ of upwelling for a halocline $200 \mathrm{~m}$ thick across the whole model Arctic basin. A rough estimate for the diapycnal diffusion coefficient required to support that level of upwelling is $\kappa=w^{*} H_{1} \approx 6 \times 10^{-6} \mathrm{~m}^{2} \mathrm{~s}^{-1}$. This is roughly in accord with observational estimates for diapycnal mixing at the base of the halocline (D'Asaro and Morison 1992; Wallace et al. 1987; Rainville and Winsor 2008). It is noted that the uncertainties in the observational estimates are large and the mixing is highly variable in space and time, so the present calculation is best viewed as simply a demonstration of how diapycnal mixing enters into the potential vorticity budget and alters the mean circulation. Mixing drives upwelling from layer 2 into layer 1 , which reduces the potential vorticity across the basin. The halocline is $10-20 \mathrm{~m}$ thicker throughout the basin, with the largest changes found near the outflow straits (Fig. 7d). Because the thickness on the boundaries does not change substantially from the central case, the increase in halocline thickness in the interior drives an enhanced anticyclonic flow over most of the basin. This also results in a slightly stronger Beaufort Gyre (Fig. 8). This is a demonstration that even very weak mixing in the Arctic Ocean may be important for the large-scale circulation. The Arctic is relatively more sensitive than the midlatitude winddriven gyres to weak mixing because the surface stress and mean circulation in the Arctic are much weaker than that found at lower latitudes.

A calculation was carried out on an $f$ plane with $f=$ $1.4 \times 10^{-4} \mathrm{~s}^{-1}$. Even though the change in $f$ is weak near the pole in the central calculation, it is still important for the circulation and halocline thickness. The primary influence of the variation in Coriolis parameter with latitude is that it causes the halocline to rotate anticyclonically relative to the applied stress. This is effectively westward around the pole. Yang et al. (2016) found a similar westward propagation for an idealized Beaufort Gyre with an artificial western boundary. The $f$-plane calculation shows an almost $1 \mathrm{~Sv}$ stronger Beaufort Gyre and a halocline that is approximately $30 \mathrm{~m}$ thicker over much of the domain (Fig. 9a). This is because the potential vorticity input by the surface stress is increased by the closer alignment between the streamfunction and stress curl. Associated with these thickness changes are enhanced anticyclonic and cyclonic circulations in the western and eastern basins.

The calculation with a continental slope added to layer 2 is shown in Fig. 9b. The primary change in the circulation is that the boundary currents are much stronger and wider, especially along the southern and western flanks of the Beaufort Gyre. The width of the boundary current is now set by the width of the topography, demonstrating a strong coupling between the two layers. The region of anticyclonic circulation now extends further westward into the region of cyclonic stress curl and the maximum transport has increased by $40 \%$ to $5.5 \mathrm{~Sv}$. The influence of a midocean ridge is shown in Fig. 9c. The boundary currents in this case compare more closely with the flat-bottom result and the TPD is directed more in the downwind direction and parallel to the ridge. The cyclonic circulation in the eastern basin has expanded and the anticyclonic circulation in the western basin has not rotated as far in the clockwise direction due to blocking of east-west exchange by the ridge. A calculation with both the slope and midocean ridge reflects influences from both topographic features (Fig. 9d). The boundary currents are strong and wide 

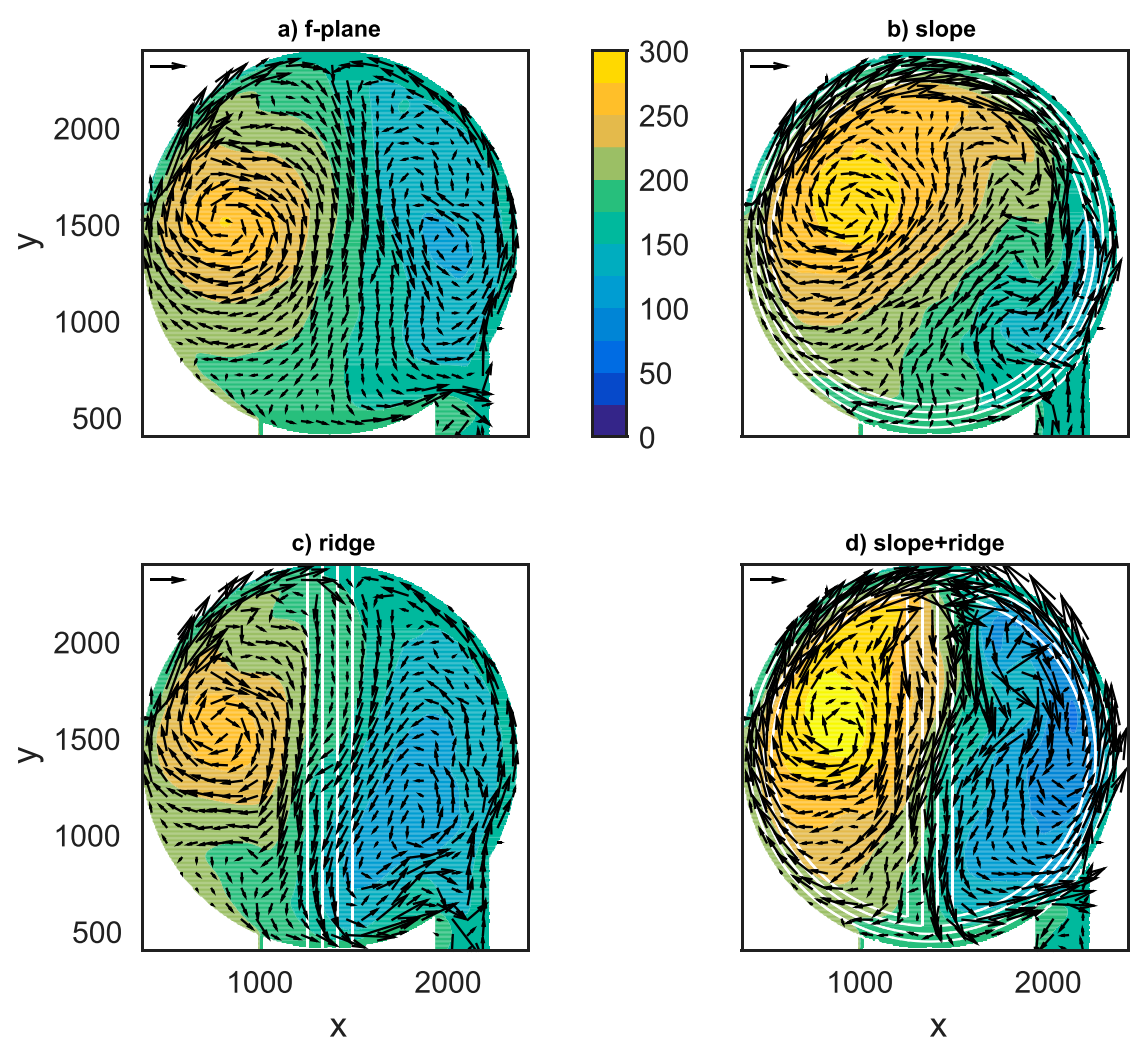

FIG. 9. Layer-1 thickness (m) and velocity (every twelfth grid point) of layer 1 for the (a) $f$ plane, (b) continental slope, (c) midocean ridge, and (d) continental slope plus midocean ridge. The vector in the upper-left corner of each panel indicates a speed of $5 \mathrm{~cm} \mathrm{~s}^{-1}$. The white contours are the bottom topography, with contour interval $40 \mathrm{~m}$.

while the TPD is more parallel to the topography. Both the anticyclonic and cyclonic gyres are larger and stronger than for the flat-bottom case (Fig. 8).

The important role of narrow viscous boundary layers in balancing the potential vorticity budget suggests the possibility that the basic structure of the basin-scale circulation could change for sufficiently large Reynolds numbers or by imposing free-slip lateral boundary conditions, as has been found for midlatitude subtropical gyre models (Blandford 1971; Jiang et al. 1995; Ierley and Sheremet 1995; Cessi and Ierley 1995). A model run with the same forcing and configuration as the central case but using free-slip boundary conditions produces a $70 \%$ stronger anticyclonic gyre that is rotated further clockwise around the basin (Fig. 10). The TPD is oriented more directly from the eastern basin toward the western basin, providing a more effective mean advection of potential vorticity from the cyclonic forcing region into the anticyclonic forcing region. In this case the ability of the viscous boundary layers to extract potential vorticity is greatly reduced relative to the no-slip case and the potential vorticity input at the surface is now largely balanced by lateral advection between gyres.
The mean potential vorticity budget averaged over the western basin $(x<1240 \mathrm{~km})$ summarizes the dynamical influences of each of these factors (Fig. 11a). The example from the previous section (central) shows that the surface stress is balanced by both friction and advection, with advection being somewhat more important. If the wind stress in the eastern basin is removed so that there is only anticyclonic curl in the western basin (BG only), the role of friction is greatly enhanced over

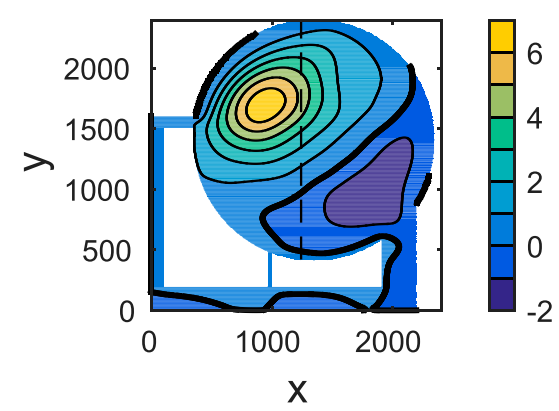

FIG. 10. Mean transport streamfunction in layer 1 for a calculation with free-slip lateral boundary conditions. 

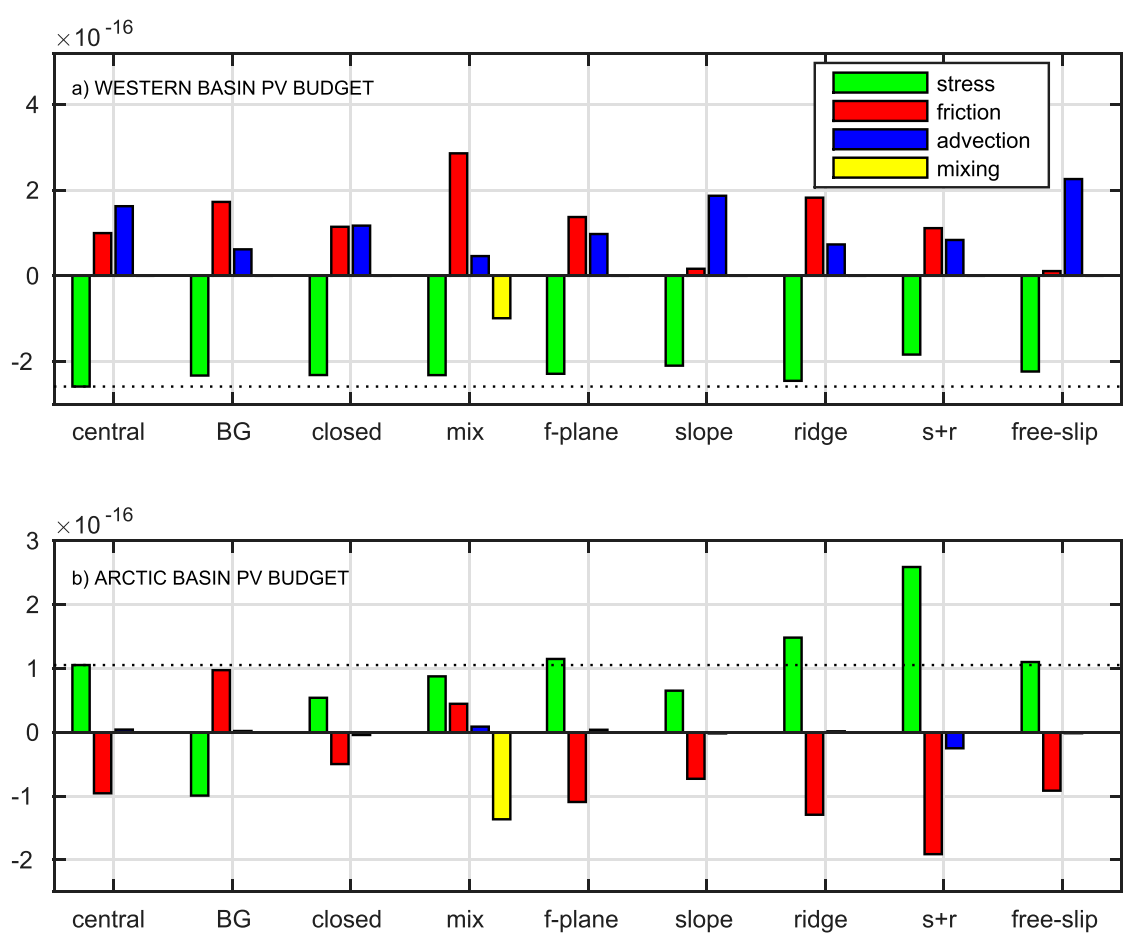

FIG. 11. Terms in the layer-1 potential vorticity equation averaged over the final 50 years of integration for (a) the western basin and (b) the whole Arctic basin for each of the model simulations discussed in the text. The dotted lines mark the surface stress for the central case for easy comparison with the other calculations.

that of advection. This is because there is no source of positive potential vorticity at the surface in the eastern basin that can balance mean advection from the anticyclonic forcing region. The potential vorticity input by the surface stress is reduced relative to the central case because the halocline is thicker in the absence of the cyclonic stress in the eastern basin and the vorticity input by the surface stress is inversely proportional to the layer thickness squared. This is another indication of the importance of advection between the eastern and western Arctic. If the basin is closed and the standard surface stress is applied (closed), advection and friction are equally important in balancing the surface stress. The potential vorticity input by surface stress is reduced in this case as well because the equilibrium halocline is deeper in the absence of the relatively high potential vorticity water input through Bering Strait. Diapycnal mixing and upwelling from the Atlantic Water layer produces anticyclonic vorticity and greatly enhances the importance of lateral friction at the boundaries. The halocline deepens to the point where the boundary currents are sufficiently strong to balance the mixinginduced reduction in potential vorticity. The calculation with a constant value of $f_{0}=1.4 \times 10^{-4} \mathrm{~s}^{-1}$ ( $f$ plane) shows enhanced friction and reduced advection but both remain important. This reduced influence of advection is because the mean advection pathways no longer cross the surface stress vector as strongly as for the central case.

The role of friction is greatly reduced for the case with the continental slope. This is because the boundary currents flow over the topography, which limits the frictional potential vorticity flux into the boundary because the boundary current is wider than the width of the frictional boundary layer. As a result, the gyres rotate further clockwise relative to the surface stress, thus reducing the potential vorticity input at the surface, and the surface forcing is almost entirely balanced by advection between the gyres. The midocean ridge enhances the role of friction and reduces advection between the gyres. The results from the coupling between the upper and lower layers and the resulting blocking of mean advection between the anticyclonic and cyclonic surface forcing regions. The final calculation with both slope and ridge shows both friction and advection are important in balancing the surface forcing. The potential vorticity input at the surface is reduced because the Beaufort Gyre is deeper and stronger than for the flat-bottom case.

A similar potential vorticity budget calculated with the average taken over the whole Arctic basin shows in general a balance between surface stress and lateral 
friction (Fig. 11b). Advection is very small, although this may be in part because the inflow and outflow in this idealized model domain are at the same latitude. For an outflow at a different latitude than the inflow there would be a flux divergence of planetary vorticity. This change would be compensated by an equal and opposite change in either surface stress or lateral dissipation. This is clear from the application of a circulation integral around the Arctic basin by Joyce and Proshutinsky (2007). The magnitudes of the terms are smaller when averaged over the whole domain because of cancellation between the cyclonic and anticyclonic regimes. As expected, the Beaufort Gyre only case has the opposite sense of vorticity input and dissipation. The closed basin case has much less potential vorticity input by the surface stress because the halocline is deeper all across the basin as a result of the lack of high potential vorticity inflow from Bering Strait. Diapycnal mixing exceeds the net cyclonic stress at the surface, resulting in an enhanced anticyclonic circulation and cyclonic vorticity production at the boundaries. The calculation with a midocean ridge has more cyclonic vorticity input because the thickness of the halocline in the eastern basin is reduced relative to the central case as a result of the blocking from the ridge and the deepening of the Beaufort Gyre under the anticyclonic forcing in the western basin. The case with both the ridge and slope has much stronger positive potential vorticity input at the surface, requiring stronger dissipation and the boundaries and even some net export through the straits. The enhanced surface forcing is a result of the reduced advection between gyres combined with the slope limiting the frictional loss at the boundaries. As a result, the equilibrated gyres are stronger, the mean layer thickness in the eastern basin in thinner, and the net positive potential vorticity input is enhanced.

\section{Summary}

The primary message from this study is that the eastern and western basins of the Arctic Ocean halocline are likely dynamically connected. This conclusion is based on results from an idealized two-layer numerical model of the Arctic that represents the primary surface forcing imposed by winds and ice motion and the flow through Bering Strait. The model produces a Beaufort Gyre and a Transpolar Drift in rough agreement with observations. The eastern and western basins are dynamically linked in two ways. First, advection between regions of anticyclonic and cyclonic forcing is of leading-order importance in closing the potential vorticity budget. This mechanism is entirely missing in idealized models of the Beaufort Gyre that have only anticyclonic forcing. This then requires that the mean potential vorticity (and thus thickness) of the halocline in both the eastern and western basins depends on the surface stress across the entire Arctic. The second way in which the eastern and western basins are linked is through the net transport of Pacific-origin water from Bering Strait to the Canadian Arctic Archipelago and Fram Strait. The net transport of approximately $1 \mathrm{~Sv}$ requires an interface displacement of $O(25 \mathrm{~m})$ across the basin. Thus, even if these Pacific-origin waters do not enter the Eurasian Basin directly their transport requires that the halocline on the eastern boundary of Fram Strait be shallower, or the thickness on the western boundary be deeper, than it would be in the absence of flow through Bering Strait. The inflow of Pacific-origin water also causes the equilibrium depth of the Beaufort Gyre to be shallower than it would be subject to wind-forcing only because it provides a source of high potential vorticity to the basin, which partially balances the anticyclonic surface forcing from the Beaufort high. These conclusions are supported through detailed potential vorticity budgets of numerous model runs with changes to the surface forcing, Bering Strait inflow, and domain configuration.

Mesoscale eddies were found to be important in the center of the Beaufort Gyre, as has been shown in previous idealized studies. However, the mean flow in the gyre was also found to be important in balancing the anticyclonic surface forcing. This is due to asymmetries in the gyre introduced by three distinct mechanisms. The first is the inflow of high potential vorticity water through Bering Strait, which flows toward the west upon entering the basin, analogous to the recently observed Chukchi Slope Current (Corlett and Pickart 2017; Spall et al. 2018). The second is because the offshore side of the anticyclonic curl region is adjacent to the Transpolar Drift instead of a solid boundary. This also provides a pathway for high potential vorticity fluid from the eastern basin to get advected into the region of anticyclonic forcing. The third asymmetry arises because the region of closed potential vorticity contours (the gyre center) propagates anticyclonically relative to the surface stress due to the variation of the Coriolis parameter with latitude. This causes the mean advective pathways to pass under regions of stronger and weaker surface forcing. The mean flow also balances the eddy flux divergence both along the gyre periphery and along the unstable inflow of Pacific-origin water. Eddies are also important in the eastern basin and along the Transpolar Drift. They generally reduce the potential vorticity under the region of cyclonic forcing and flux potential vorticity down gradient across the Transpolar Drift. The mean circulation balances this eddy flux divergence as the eddies decay away from their formation regions. It is 
also noted that at this grid spacing the model is eddy permitting but not eddy resolving. Higher-resolution (Reynolds number) calculations may result in stronger eddy fluxes and boundary currents and an enhanced role for advection in the potential vorticity budget.

The mean halocline thickness is ultimately determined by the balance between potential vorticity input at the surface and dissipation at the boundaries. The advective flux divergence resulting from the transport in/out of the straits is small. However, the strait transports, presence of topography and diapycnal mixing strongly influence the mean halocline thickness across the Arctic. This is in part because the net vorticity flux at the surface itself depends on the halocline thickness. Thus, for example, processes that lead to a thinner halocline in the eastern basin result in more positive potential vorticity input at the surface and thus require stronger dissipation of cyclonic vorticity at the boundaries. The advective terms are required to carry the fluid from the basin interior, where it gains or loses potential vorticity due to surface forcing, to the boundaries where it is dissipated. Anything that alters either the vorticity input from surface forcing or the ability of mean and eddy fluxes to carry that vorticity to the boundaries will alter the mean halocline thickness. Bottom topography influences the mean circulation by altering the exchange between eastern and western basins. A midocean ridge inhibits the exchange, thus requiring a more local balance between surface forcing and friction at the boundaries. However, a continental slope reduces the friction loss at the boundaries and enhances the role of advection between basins. The present model is not realistic enough to identify which of these processes is dominant in the real Arctic Ocean but it does identify their respective roles in governing the potential vorticity budget and thus the mean circulation and halocline thickness.

The wind-driven Arctic Ocean general circulation has some elements in common with classical midlatitude and Southern Ocean general circulation theories. The structure of anticyclonic and cyclonic surface forcing, potential vorticity fluxes between gyres, and dissipation at the lateral boundaries are similar to the midlatitude subtropical/subpolar gyres. However, the Arctic is fundamentally different in that it lacks a well-defined western boundary, which is of course central to midlatitude wind-driven ocean circulation theory. The balance between Ekman pumping and lateral eddy fluxes within the anticyclonic Beaufort Gyre is similar to the Southern Ocean, but the Arctic also has an opposite sign of potential vorticity input at the surface in the Eurasian Basin, so connectivity between gyres, modulated by the midocean ridges, source of high potential vorticity
Pacific Water, and lateral boundaries are extra factors not found in the Southern Ocean. Sensitivity to the lateral boundary layers also suggests the possibility of multiple equilibria or fundamentally different mean circulations for larger Reynolds number configurations, as has been found for midlatitude wind-driven gyres (Blandford 1971; Jiang et al. 1995; Ierley and Sheremet 1995; Cessi and Ierley 1995).

Acknowledgments. This study was supported by National Science Foundation Grant OPP-1822334. Comments and suggestions from two anonymous referees greatly helped to improve the paper.

\section{REFERENCES}

Aagaard, K., J. Swift, and E. Carmack, 1981: On the halocline of the Arctic Ocean. Deep-Sea Res., 28, 529-545, https://doi.org/ 10.1016/0198-0149(81)90115-1.

Aksenov, Y., and Coauthors, 2016: Arctic pathways of Pacific water: Arctic ocean model intercomparison experiments. J. Geophys. Res. Oceans, 121, 27-59, https://doi.org/10.1002/ 2015JC011299.

Andrews, D. G., and M. E. McIntyre, 1976: Planetary waves in horizontal and vertical shear: The generalized Eliassen-Palm relation and the mean zonal acceleration. J. Atmos. Sci., 33, 2031-2048, https://doi.org/10.1175/1520-0469(1976)033<2031: PWIHAV $>2.0 . \mathrm{CO} ; 2$.

Blandford, R. R., 1971: Boundary conditions in homogeneous models. Deep-Sea Res. Oceanogr. Abstr., 18, 739-751, https:// doi.org/10.1016/0011-7471(71)90088-X.

Blumsack, S. L., and P. J. Gierasch, 1972: Mars: The effects of topography on baroclinic instability. J. Atmos. Sci., 29, 1081-1089, https://doi.org/10.1175/1520-0469(1972)029<1081: MTEOTO $>2.0 . \mathrm{CO} ; 2$.

Cessi, P., and G. R. Ierley, 1995: Symmetry-breaking multiple equilibria in quasigeostrophic, wind-driven flows. J. Phys. Oceanogr., 25, 1196-1205, https://doi.org/10.1175/15200485(1995)025<1196:SBMEIQ>2.0.CO;2.

Corlett, W., and R. S. Pickart, 2017: The Chukchi slope current. Prog. Oceanogr., 153, 50-65, https://doi.org/10.1016/ j.pocean.2017.04.005.

Davis, P. E. D., C. Lique, and H. L. Johnson, 2014: On the link between Arctic Sea Ice decline and the freshwater content of the Beaufort Gyre: Insights from a simple process model. J. Phys. Oceanogr., 33, 8170-8184, https://doi.org/10.1175/ JCLI-D-14-00090.1.

D'Asaro, E., and J. H. Morison, 1992: Internal waves and mixing in the Arctic Ocean. Deep-Sea Res., 39A, S459-S484, https:// doi.org/10.1016/S0198-0149(06)80016-6.

Fox-Kemper, B., 2005: Reevaluating the roles of eddies in multiple barotropic wind-driven gyres. J. Phys. Oceanogr., 35, 1263-1278, https://doi.org/10.1175/JPO2743.1.

Haine, T. W. N., and Coauthors, 2015: Arctic freshwater export: Status, mechanisms, and prospects. Global Planet. Change, 125, 13-35, https://doi.org/10.1016/j.gloplacha.2014.11.013.

Haynes, P. H., and C. E. McIntyre, 1987: On the evolution of vorticity and potential vorticity in the presence of diabatic heating and frictional or other forces. J. Atmos. Sci., 44, 828-841, https:// doi.org/10.1175/1520-0469(1987)044<0828:OTEOVA >2.0.CO;2. 
Ierley, G. R., and V. A. Sheremet, 1995: Multiple solutions and advection-dominated flows in the wind-driven circulation. Part I: Slip. J. Mar. Res., 53, 703-737, https://doi.org/10.1357/ 0022240953213052.

Isachsen, P., 2011: Baroclinic instability and eddy tracer transport across sloping bottom topography: How well does a modified Eady model do in primitive equation simulations? Ocean Modell., 39, 183-199, https://doi.org/ 10.1016/j.ocemod.2010.09.007.

Jiang, S., F.-F. Jin, and M. Ghil, 1995: Multiple equilibria, periodic, and aperiodic solutions in a wind-driven, double-gyre, shallowwater model. J. Phys. Oceanogr., 25, 764-786, https://doi.org/ 10.1175/1520-0485(1995)025<0764:MEPAAS > 2.0.CO;2.

Jones, E. P., L. G. Anderson, and J. H. Swift, 1998: Distribution of Atlantic and Pacific waters in the upper Arctic Ocean: Implications for circulation. Geophys. Res. Lett., 25, 765-768, https://doi.org/10.1029/98GL00464.

Joyce, T. M., and A. Proshutinsky, 2007: Greenland's island rule and the Arctic Ocean circulation. J. Mar. Res., 65, 639-653, https://doi.org/10.1357/002224007783649439.

Lozier, M. S., and S. C. Riser, 1990: Potential vorticity sources and sinks in a quasigeostrophic ocean: Beyond western boundary currents. J. Phys. Oceanogr., 20, 1608-1627, https://doi.org/ 10.1175/1520-0485(1990)020<1608:PVSASI >2.0.CO;2.

Manucharyan, G., and M. A. Spall, 2016: Wind-driven freshwater buildup and release in the Beaufort Gyre constrained by mesoscale eddies. Geophys. Res. Lett., 43, 273-282, https:// doi.org/10.1002/2015GL065957.

- and P. E. Isachsen, 2019: Critical role of continental slopes in halocline and eddy dynamics of the Ekman-driven Beaufort Gyre.J. Geophys. Res. Oceans, 124, 2679-2696, https://doi.org/ 10.1029/2018JC014624.

— - M. A. Spall, and A. F. Thompson, 2016: A theory of the wind-driven Beaufort Gyre variability. J. Phys. Oceanogr., 46, 3263-3278, https://doi.org/10.1175/JPO-D-16-0091.1.

Marshall, J., and T. Radko, 2003: Residual-mean solutions for the Antarctic Circumpolar Current and its associated overturning circulation. J. Phys. Oceanogr., 33, 2341-2354, https://doi.org/ 10.1175/1520-0485(2003)033<2341:RSFTAC $>2.0$.CO;2.

Marshall, J. C., 1984: Eddy mean flow interaction in a barotropic ocean model. Quart. J. Roy. Meteor. Soc., 110, 573-590, https:// doi.org/10.1002/qj.49711046502.

Meneghello, G., J. Marshall, J.-M. Campin, E. Doddridge, and M.-L. Timmermans, 2018: The ice-ocean governor: Ice-ocean stress feedback limits Beaufort Gyre spin-up. Geophys. Res. Lett., 45, 11293-11 299, https://doi.org/10.1029/2018GL080171.

Østerhus, S., and Coauthors, 2019: Arctic Mediterranean exchanges: A consistent volume budget and trends in transports from two decades of observations. Ocean Sci., 15, 379-399, https://doi.org/10.5194/os-15-379-2019.

Rainville, L., and P. Winsor, 2008: Mixing across the arctic ocean: Microstructure observations during the Beringia 2005 expedition. Geophys. Res. Lett., 35, L08606, https://doi.org/10.1029/ 2008 GL033532.
Rudels, B., 2012: Arctic Ocean circulation and variability Advection and external forcing encounter constraints and local processes. Ocean Sci., 8, 261-286, https://doi.org/10.5194/ os-8-261-2012.

_ L. L. Anderson, and E. Jones, 1996: Formation and evolution of the surface mixed layer and halocline of the Arctic Ocean. J. Geophys. Res., 101, 8807-8821, https://doi.org/10.1029/ 96JC00143.

Shimada, K., M. Itoh, S. Nishino, F. McLaughlin, E. Carmack, and A. Proshutinsky, 2005: Halocline structure in the Canada Basin of the Arctic Ocean. Geophys. Res. Lett., 32, L03605, https://doi.org/10.1029/2004GL021358.

Smagorinsky, J., 1963: General circulation experiments with the primitive equations: I. The basic experiment. Mon. Wea. Rev., 91, 99-164, https://doi.org/10.1175/1520-0493(1963)091<0099: GCEWTP $>2.3 . C O ; 2$.

Spall, M. A., 2019: Dynamics and thermodynamics of the mean transpolar drift and ice thickness in the Arctic Ocean. J. Climate, 32, 8449-8463, https://doi.org/10.1175/JCLI-D-19-0252.1.

- R. S. Pickart, P. S. Fratantoni, and A. J. Plueddemann, 2008: Western Arctic shelfbreak eddies: Formation and transport. J. Phys. Oceanogr., 38, 1644-1668, https://doi.org/10.1175/ 2007JPO3829.1.

,,-- M. Li, P. Lin, T. Kikuchi, and Y. Qi, 2018: Transport of Pacific water into the Canada basin and the formation of the Chukchi slope current. J. Geophys. Res. Oceans, 123, 7453-7471, https://doi.org/10.1029/2018JC013825.

Timmermans, M.-L., and Coauthors, 2014: Mechanisms of Pacific summer water variability in the Arctic's Central Canada basin. J. Geophys. Res. Oceans, 119, 7523-7548, https://doi.org/10.1002/ 2014JC010273.

Wallace, D. W. R., R. M. Moore, and E. P. Jones, 1987: Ventilation of the Arctic Ocean cold halocline: Rates of diapycnal and isopycnal transport, oxygen utilization and primary production inferred using chlorofluoromethane distributions. DeepSea Res., 34, 1957-1979, https://doi.org/10.1016/0198-0149(87) 90093-8.

Woodgate, R. A., 2018: Increases in the Pacific inflow to the Arctic from 1990 to 2015, and insights into seasonal trends and driving mechanisms from year-round Bering Strait mooring data. Prog. Oceanogr., 160, 124-154, https://doi.org/10.1016/ j.pocean.2017.12.007.

_ ventilation of the Arctic Ocean's lower halocline by upwelling and diapycnal mixing over the continental margin. Geophys. Res. Lett., 32, L18609, https://doi.org/10.1029/2005GL023999.

_ - T. J. Weingartner, and R. Lindsay, 2012: Observed increases in Bering Strait oceanic fluxes from the Pacific to the Arctic from 2001 to 2011 and their impacts on the Arctic Ocean water column. Geophys. Res. Lett., 39, 2012GL054092, https:// doi.org/10.1029/2012GL054092.

Yang, J., A. Proshutinsky, and X. Lin, 2016: Dynamics of an idealized Beaufort Gyre: 1. The effect of a small beta and lack of western boundaries. J. Geophys. Res. Oceans, 121, 1249-1261, https://doi.org/10.1002/2015JC011296. 